ISSN: $1130-3743$

\title{
A ESTÉTICA COMO FACTOR PROMOTOR DA APRENDIZAGEM
}

\section{Aesthetics as a motivational factor for learning}

\section{Esthetique comme un facteur de motivation pour l'apprentissage}

\begin{abstract}
Fátima Maria BeZerra BARBOSA* y Margarita PINO-Juste**
* Universidade do Minho. Instituto de Educação. Departamento de Teoria da Educação e Educação Artística e Física. Campus de Gualtar. 4710 Braga (Portugal). Correo-e: fbarbosa@ie.uminbo.pt

** Universidad de Vigo. Facultade de Ciencias de la Educación e do Deporte. Departamento de Didáctica, Organización Escolar e Metodos de Investigación. Campus de Pontevedra. Correo-e: mpino@uvigo.es
\end{abstract}

Fecha de recepción: marzo de 2011

Fecha de aceptación definitiva: julio de 2011

Biblid [(1130-3743) 23, 2-2011, 91-109]

RESUMEN

La reflexión filosófica sobre el arte, lo hermoso, lo bueno, lo verdadero y su capacidad de promover el desarrollo humano es un tema que remonta a Platón en la cultura occidental.

Considerando que la educación debe ser entendida como un fenómeno integral, que abarca no sólo las dimensiones intelectuales sino también las dimensiones sensibles, la intuición y el raciocinio, las capacidades imaginativas y creativas, el "saber ser" y el "saber estar" parejas del "conocer" y del "saber hacer", pensamos que es incuestionable la importancia de la estética en el fenómeno educativo.

El objetivo de este trabajo es demostrar la importancia de la educación estética como motor fundamental de desarrollo humano y, en este sentido, como catalizador 
de la motivación y del aprendizaje, para que, a través de la imaginación y de la creatividad, sea posible la innovación en la construcción de vías alternativas para un mundo más humano y placentero.

Palabras clave: estética, aprendizaje, motivación, creatividad, imaginación.

\section{SUMMARY}

The philosophical reflection about art, beauty, good, truth, and their ability to produce pleasure in people comes from Platon in our western culture.

Considering that education must be understood as an integral phenomenon, encompassing not only the intellectual dimension but also the sensitive, intuitive and rationing dimensions, and imaginative and creative abilities, "knowing to be" is linked to "know" and "knowing-how". We think the importance of aesthetics as a motivation factor for learning is unquestionable and, through imagination and creativity, innovation in the construction of alternative roads for a more human and pleasant world can be promoted.

Key words: aesthetics, learning, motivation, creativity, imagination.

\section{SOMMAIRE}

La réflexion philosophique sur l'art, le beau, le bon, le vrai et la capacité de ceux-ci susciter le plaisir dans l'homme remonte, dans la culture de l'ouest, à Platon.

Vu que l'éducation devrait être comprise comme un phénomène intégral qui n'embrasse pas seulement les dimensions intellectuelles mais aussi les dimensions sensibles, l'intuition et le raisonnement, les capacités imaginatives et créatives, "Savoir pour être" en concurrence avec le "connaitre" et le "savoir-faire", nous pensons être incontestable l'importance de l'esthétique dans le phénomène pédagogique. Le but de cette étude, c'est celui de démontrer l'importance de l'éducation esthétique, comme le facteur de la motivation, pour enrichir les apprentissages mentionnées et que, par le truchement de l'imagination et de la créativité, soit possible promouvoir l'innovation dans la construction des voies alternatives pour un monde plus humain et de jouissance.

Mots clés: esthétique, apprentissage, motivation, créativité, imagination.

\section{INTRODUÇÃO}

O debate e a reflexão sobre a estética como forma de conhecimento e a sua importância para a educação é um tema antigo. No entanto pensamos que os contributos da estética para a área da educação são fundamentais e configuram um tema de debate que nos provoca e desafia. 
Usando as palavras de Lipovetsky (2008), a nossa sociedade é entendida como a sociedade da decepção, e é profundamente marcada pelo paradigma económico e pela procura incessante da qualidade de vida ligada ao material. Fenómenos como a globalização, a heterogeneidade de valores e a desmistificação do futuro que a ciência, pese embora a sua importância, possibilitou, necessitam de uma mensagem aglutinadora que abra caminhos alternativos e possibilite novos rumos pedagógicos (Bezerra Barbosa, 2011).

A educação, e fundamentalmente a educação formal, desde sempre, potenciou o conhecimento racional deixando descobertas, ou relegadas para segundo plano, áreas do saber ligadas à sensibilidade, à emoção, ao prazer, à criatividade e à imaginação. Sabemos, também, que é pela criatividade que se desenvolve a capacidade de experimentar, de partilhar, de jogar, de inventar, de fantasiar e de harmonizar, tão importantes para o desenvolvimento integral, aberto, consciente e crítico do ser humano. Todas estas competências, ou capacidades básicas, que potenciam o educar com originalidade e a transmissão dos conteúdos escolares de forma criativa e activa, podem ser potenciadas se tivermos em consideração as possibilidades que nos oferece a estética no âmbito educativo.

Na verdade, ao adquirir os conhecimentos duma forma sensível e não abstracta, sem nos importarmos com a sua utilidade imediata, estamos a contrariar um mundo que privilegia essencialmente o valor de troca, uma vez que, como poderemos comprovar, a beleza em si não é quantificável através de valores económicos.

O objectivo da educação será converter a realidade consumista actual em novos sonhos, novas realidades, novas formas de ser e estar no mundo, que apontem novos sentidos para a satisfação e a realização individual e para novas organizações sociais.

A educação dos e pelos sentidos, ou seja, a educação estética, ajuda-nos a formar indivíduos autênticos, auto-confiantes, tolerantes e abertos, capazes de enfrentar a hegemonia do pensamento único, o dogmatismo e os poderes instalados. A felicidade e o bem-estar não radicam no materialismo mas na possibilidade de ensaiar e reconstruir, com paixão, as nossas experiências e as nossas vivências. Poderemos assim cumprir os objectivos da educação integral que significa "formar a partir da inteligência, vontade e afectividade com o objectivo de confrontar com liberdade e possibilidades de êxito as diferentes situações com que nos deparamos nos vários âmbitos da vida (pessoal, familiar, social, profissional, etc.)" (Touriñán e Longueira, 2010, 157). Aprendemos assim a conviver melhor, a respeitar a diferença, a confiar, a melhorar as relações interpessoais, a enfrentar desafios e a descobrir caminhos alternativos, acabando com o mal-estar que se respira nas escolas e nas instituições sociais. A beleza, objecto da estética, não é um fenómeno específico da arte ou da natureza, mas deve ser entendida como "inclusividade" no ser. Os objectos estéticos dirigem-se a um sujeito integral, ao ser humano na posse de todas as suas faculdades, o que implica uma vertente sensível e emocional e, uma vertente inteligível constituída pelo entendimento e pela razão. Neste sentido, a obra de arte dirige-se e afecta a unicidade ontológica de cada um que é, simultaneamente, a unicidade do próprio universo. 
O mundo humano sendo um mundo cultural revela a natureza como uma realidade humanizada, como natureza cultural, daí o papel fundamental da educação nas sociedades contemporâneas, visando a possibilidade de integrar e proporcionar identidade aos indivíduos e aos "Sócios", os concidadãos. Neste sentido a estética terá de ser entendida não só como mais uma via a considerar no processo educativo, mas como o próprio motor da educação. De facto, se analisarmos a história da humanidade verificamos que através dos tempos as manifestações estéticas acompanharam o desenvolvimento humano, quer nas suas manifestações privadas, quer nas suas manifestações públicas. Daí considerarmos a estética não só como uma estratégia mas como um princípio da própria humanização. Assim, estética e a arte surgem como essenciais para a devolução da confiança, da auto-estima e da possibilidade de encarar o futuro com mais optimismo, ou seja, para a promoção de um projecto educativo que se pretende crítico e emancipatório.

O prazer que nos produz o belo, separa-nos totalmente do mundo animal pois este não é só uma apreciação sensorial mas requer a aplicação de conhecimentos e habilidades cognitivas complexas, só deste modo podemos apreciar a beleza de um poema, um quadro ou de uma peça musical.

Realmente, a educação estética tem por objecto desenvolver no ser humano a capacidade para captar, distinguir e expressar beleza (Oriol de Alarcón, 2005). O olhar estético é um olhar filosófico sobre a vida onde a arte se inclui. Relativamente arte, impele o criador e o fruidor a realizar ou visualizar uma determinada obra artística sob o ponto de vista crítico, facilitando a compreensão do valor universal e excepcional da obra.

A estética é algo que provoca o homem, questiona-o, fá-lo reflectir sobre as coisas, belas ou horríveis. As respostas estéticas são desencadeadas por situações ou objectos agradáveis, bonitos ou de "arte séria" e; de igual modo, podem ser evocadas a partir de situações e de objectos feios, inquietantes ou vãos (Hargreaves, 1991). Daqui se conclui que a categoria "de estético" não está ligada unicamente à arte do belo, encontra-se também na natureza, na técnica, na indústria, nas novas tecnologias, na vida pública ou privada, nos locais de trabalho ou de lazer, em casa ou na rua (Vásquez, 2008).

Também Wolfgang Fritz Haug sugere algo semelhante quando tenta definir este conceito de um modo que poderia chegar a confundir alguns leitores que o associam fortemente com a arte, utilizando-o no sentido cognitivo sensitivo, como um conceito para designar o conhecimento sensível (Haug, 1989).

Deste modo, a educação dos sentidos, base da estética, não é mais do que «um processo cognitivo interno provocado por uma assimilação perceptiva e sensual de uma realidade vivida através dos sentidos" (Collelldemont i Pujadas, 2002, 11) permitindo-nos olhar o mundo de um modo diferente, criando sentidos novos para a nossa própria vida e para a forma de nos relacionamos com os outros.

Muitas vezes a educação estética limita-se à educação artística, uma parte fundamental sem dúvida, mas não a única. A percepção estética e a percepção artística têm, critérios coincidentes. Estes critérios artísticos e estéticos são convencionais e 
mudam em função das ideias, da época e da cultura, o que determina a coincidência entre o artístico e o estético.

Partindo do princípio que a educação possibilita o desenvolvimento das capacidades e potencialidades do educando ao máximo, e tendo em conta que a educação estética o pode conseguir, não se entende porque é que essa oportunidade não é potenciada ao longo de todo o processo educativo abrangendo todas as fases etárias ou seja, de forma permanente ao longo da vida.

De acordo com Morin (1999), há sete conhecimentos fundamentais que a educação do futuro deveria desenvolver em todas as sociedades e culturas, respeitando os usos e costumes específicos de cada uma.

Neste sentido, sabemos todos que a educação privilegia a comunicação de conhecimentos, no entanto, não promove a reflexão sobre o que é o conhecimento humano, as disposições, as imperfeições, as dificuldades, tendências, erros e fantasias, não se preocupando com a explicação do que é conhecer. Torna-se assim necessário introduzir e desenvolver na educação o estudo de toda a complexidade humana, dos seus processos e modalidades, das disposições psíquicas e culturais que permitem arriscar o erro e a fantasia.

Do mesmo modo é necessário tratar os problemas globais e fundamentais inscrevendo neles conhecimentos parciais e locais, ou seja, operar o vínculo entre as partes e a totalidade.

Outra realidade fundamental, muitas vezes ignorada pela educação, é o destino planetário do género humano. A compreensão e a harmonia devem ser o princípio e o fim do processo educativo. As ciências fizeram-nos adquirir muitas certezas mas, simultaneamente, revelaram-nos, no século XX, incontáveis campos de incerteza.

Deste modo, pensamos ser necessário repensar a educação a partir da estética, implementando ao longo do processo educativo estratégias que permitam enfrentar os riscos, o inesperado, o incerto, e modificar o desenvolvimento de acordo com esta visão harmónica do mundo.

É urgente abordar o fenómeno educativo de diversos pontos de vista, equacionar diferentes perspectivas e dominar diferentes estratégias que, para nós, passam pelo desenvolvimento da sensibilidade da imaginação e da criatividade. Pensamos que a perspectiva estética pode ser a chave que nos permite abrir portas novas na educação.

E preciso contactar com as formas da natureza e com as obras de arte produzidas pelos homens, cultivando a sensibilidade, motivando a criatividade e desenvolvendo um processo de individualização integrada com o meio social e as suas instituições (Read, 2007).

O nosso objectivo, neste trabalho, é precisamente demonstrar a importância da estética na educação. Dado a complexidade e a magnitude deste desiderato, vamos centrar-nos essencialmente na educação formal e, dentro desta, analisar a estética como factor de motivação para a aprendizagem. 


\section{ESTÉTICA E APRENDIZAGEM}

As sucessivas aproximações, empíricas, filosóficas e científicas demonstram a real conexão entre estética, prazer e aprendizagem, o que torna evidente a necessidade de explicitar e promover estas qualidades, em tudo aquilo que envolve a tarefa educativa.

O ideal estético é aplicável a muitas das variáveis que estão presentes nos processos educativos, basta observarmos o processo de evolução que, a este respeito, sofreram os livros de texto. O aspecto gráfico do texto modificou-se e tornou-se mais atractivo, favorecendo assim a sua compreensão. Os conteúdos, sofreram também modificações adequando-se às exigências dos discentes. Não podemos esquecer que a descodificação aplicada a qualquer nível (icónico ou verbal) é também uma fonte de prazer (Birkhoff, 1933). Estas questões permitem-nos falar do texto, como uma produção artística industrial uma vez que maneja as variáveis que ligam a estética e o prazer para produzir, neste caso, uma aprendizagem.

O livro, é apenas um elemento que tomamos como exemplo, onde se podem avaliar as alterações estéticas introduzidas tendo em vista melhorar a aprendizagem.

Como podemos intuir, estudar a qualidade estética como factor positivo para a aprendizagem e reflectir sobre a importância da educação estética para o desenvolvimento do ser humano é muito importante, não só porque "um ambiente estético apropriado provoca reacções emocionais positivas, sensação de bem-estar, satisfação e confiança" (Suárez Pazos, 1987, 308), o que favorece os processos de aprendizagem, mas também porque, ensinar as crianças a apreciar esteticamente, logo desde os primeiros anos, cria as bases para o desenvolvimento do seu potencial criativo, enriquece a formação e desenvolvimento de novas ideias educando-as culturalmente para interpretar, a partir de dados sensíveis, os diferentes processos sociais (Barba Téllez e García Bargado, 2006).

Estas premissas são apenas evidências da necessidade de uma educação estética. De facto, Gennari (1997) quando analisa o "sensus aestheticus" do homem contemporâneo indica que, muito embora a diminuição de sensibilidade estéticoartística, o ser humano actual é portador de um projecto de educação estética que o acompanha ao longo da vida.

Cada indivíduo é responsável pelo seu projecto educativo. Este constitui-se por um "a fazer" que, embora condicionado pela sociedade e a cultura, não se realiza nunca sem a adesão do sujeito a uma finalidade que entende como desejável. Desta finalidade fazem parte elementos relacionados com a afectividade, a emotividade, os sonhos e os desejos, ou seja, "os interesses" e, simultaneamente, as ferramentas que lhe permitem subsistir no meio natural e social onde habita, as suas "necessidades" (Barbosa, 2008).

Assim, a finalidade da educação estética seria a de promover no estudante a plena realização de sua vida, aperfeiçoando todas as suas as qualidades humanas. O desenvolvimento desta capacidade requer estar atento à problemática da beleza (Caranfa, 2007). Quando os alunos conseguem apreciar a beleza à sua 
volta desenvolvem a capacidade de a transferir para outras áreas que afectam a vida quotidiana, social, profissional e, simultaneamente, isto reflecte-se na sua auto-estima e, nas relações que estabelecem com os outros e com o mundo.

Entendemos a educação estética, como educação dos sentidos base da consciência e, portanto, da inteligência e do juízo dos indivíduos (Read, 1996, 33).

O valor da componente estética é, assim, fundamental, uma vez que serve como reforço das situações de aprendizagem ao proporcionar contextos perceptivamente gratificantes, estimula a criatividade e capacita para a competência social já que, a escola como espaço público é o lugar físico de passagem, estadia e convívio social, onde se estabelecem constantes relações diárias de comunicação (Pareyson, 1997). Os efeitos estéticos que provocam a configuração deste espaço estão intimamente relacionados com as normas éticas que regulam o seu uso. Normas que, por serem de natureza cultural e histórica, são diferentes em cada comunidade e em cada momento.

Vários autores (Gutiérrez Pérez, 1998; Ruiz Ruiz, 1994 e Heras Montoya, 1997) são unânimes na necessidade de considerar que é necessário prestar atenção à organização e ao uso do espaço físico este é, também, um factor decisivo da motivação, do interesse, da participação e da integração das pessoas. A importância da arquitectura do espaço escolar na formação dos alunos é referida por alguns (Crespo Comesaña e Pino Juste, 2003, 2009) e a sua importância na qualidade de vida é também evidenciada (Aznar e Pino Juste, 2009; Pino Juste e Bezerra Barbosa, 2007).

Deste ponto de vista, a educação estética contribui para o desenvolvimento global do indivíduo: corpo e mente, sensibilidade inteligência, sentido estético, desenvolvimento de habilidades sócio afectivas e reforço da auto-estima. A interacção entre a escola e os diferentes contextos educativos, escolares e extra-escolares, permite múltiplos factores formativos (Gennari, 1997). Mas é necessário não esquecer que não se trata apenas de levar os alunos a visitar os museus ou bibliotecas, mas que realmente se realizem projectos que enriqueçam os conhecimentos que se adquirem na escola, em interacção com os diferentes meios culturais.

Quando nos referimos à educação estética, associamo-la, frequentemente, ao ensino da arte; porém, a estética, como componente de um projecto de educação de jovens e adultos, remete-nos a uma metodologia enriquecida por aspectos que são peculiares da arte, mas que também se encontram noutras áreas do conhecimento e da vida dos indivíduos. No nosso século a estética é muito mais que a teoria filosófica do belo e do bom gosto ou seja, a estética invadiu todos os âmbitos de vida (Perniola, 1997).

O valor da componente estética não pode ser considerado unicamente pela qualidade que acompanha as variáveis envolvidas nas situações de ensino-aprendizagem. A estética é um campo de conhecimento autónomo pelo que as suas componentes são susceptíveis de serem ensinadas e aprendidas. Em geral, entendemos por educação estética a educação dos sentidos sobre os quais se baseia a consciência e, em última estancia, a inteligência e o juízo do indivíduo (Read, 1996). 
Assim a estética possibilita o conhecimento do mundo a partir dos dados dos sentidos, através deles as sensações são "interiorizadas" e "activadas" na contemplação, o que possibilita a criação de formas diferentes de saber a realidade, ou seja, conhecer esteticamente implica a união da sensibilidade e do intelecto.

Através da contemplação estética, iniciamos uma exploração activa, que parte da sensibilidade e propicia uma forma de ver racionalmente diferente, uma vez que sintetizamos o que se vê com o que se esperava ver. É aqui que radica a função prospectiva implícita no conhecimento estético (Barbosa, 2011). Como consequência, consideramos que a educação estética é uma via essencial, e pouco estudada, para o desenvolvimento pessoal e social.

Para trabalhar os elementos relacionados com a aprendizagem estética Juanola e Balada (1987), enfatizaram a necessidade de introduzir a criança, o mais cedo possível no mundo visual, como canal preponderante da percepção que integra o eu, no espaço, na sociedade e na época, e se relaciona estreitamente com a compreensão do contexto sociocultural. No entanto pensamos que a apreciação estética deve ser um processo que se estende ao longo da vida e que abarca todos os contextos onde esta se desenrola. É um processo comprometido com o amor e com o discernimento, com a procura das razões que justificam a extraordinária sensação de prazer perante um determinado estímulo.

Neste sentido, a componente estética é uma ferramenta na qual o professor deve apoiar o seu trabalho e, ao mesmo tempo, um conteúdo de aprendizagem.

\section{ESTÉTICA E CRIATIVIDADE}

O tema da educação estética (Schiller, 1968; Popper, 1989; Arnheim, 1993; Gennari, 1997) e da criatividade (Aguirre, 2000; Oriol de Alarcón, 2001; Monreal 2001) foi estudado por diferentes autores no último século. Podemos também encontrar inúmeros estudos sobre experiências que fomentmr a criatividade (Pirini, 2002; Betancourt y Valadez, 2000; Bronstein y Vargas, 2001; Marín e De la Torre, 1991) e até mesmo sobre a importância da criatividade para o desenvolvimento económico e social. De facto, constata-se que a sociedade se encontra numa época de grande mudança provocada essencialmente pelo fenómeno da globalização, o rápido desenvolvimento das tecnologias e a deterioração do equilíbrio planetário. É verdade também que apenas uma minoria de pessoas é sensível aos processos de mudança social. Desta forma, desenvolver a criatividade pode ser o ponto de referência para que surja um futuro diferente que tenha como resultado uma transformação social e uma nova cultura (Ray e Anderson, 2000; Florida, 2002).

O pensamento criativo é aquele capaz de fazer crescer o olhar dos indivíduos por meio de metáforas e representações emotivas (subjectivas) das coisas sem necessidade de usar raciocínios lógicos (objectivos). Através do livre jogo e de associações metafóricas, incorporamos no nosso conhecimento do mundo a nossa própria criatividade, originando a inovação. 
A potenciação da experiência estética permite, em nossa opinião, implementar desde criança, novas vias de comportamento que levarão ao aparecimento de um novo homem e que a qualidade das memórias, voluntárias ou involuntária, têm sem dúvida uma função mais valiosa e mais transcendente que a meramente acumulativa, a de traduzir em valores morais a experiência pessoal dentro do grupo e a de harmonizar, de modo criativo, a relação consigo, com os outros e com o mundo (Flores, 1996), o que implica potencializar o conhecimento através do contacto com a arte, de modo a facilitar a criatividade individual, uma vez que consideramos que a criatividade é essencial em qualquer tipo de conhecimento. Esta conforma-se ao longo da vida, em função das influências históricas, sociais e culturais com as quais o indivíduo interactua (Mitjáns, 1995).

Por tanto, a criatividade é uma experiência profundamente imbricada no próprio acto de aprender, assente na capacidade de descobrir, de encontrar, de manifestar, de tornar patente ou formalizar ideias e experiências relativamente originais ou novas (Herrán Gascón, 2000). Não podemos esquecer que a característica que distingue a criatividade em todos os campos sejam artísticos ou de criação industrial, tanto na pintura como na literatura, na ciência como na tecnologia, é a criatividade envolvida com o aparecimento de novas rotas neurológicas, entendidas como desenvolvimento e expressão de processos e acções associadas ao encontro pessoal e ao espanto relativo. Globalmente, por criatividade entendeu-se a capacidade de dar respostas, elaborar ou inventar produções originais, valiosas, ou de se questionar e resolver problemas de um modo invulgar. A capacidade para trabalhar todos estes aspectos vai ser proporcionada por uma perspectiva integral da aprendizagem, na convicção da importância do desenvolvimento do potencial criativo, vinculado ao trabalho reflexivo sobre a experiência da apreciação estética.

Partindo da recepção dos dados sensíveis, e deste trabalho reflexivo sobre a experiência, activam-se em nós outras sensações, imagens inconscientes que, através desta experiência se tornam possibilidades. Segue-se um processo em que o entendimento se une à sensibilidade e dá lugar ao conhecimento.

Este conhecimento estético-criativo é um conhecimento próprio, "o jogo estético é um acto de liberdade espiritual" (Roura-Parella, 2002, 9) que leva a intuir novas formas de ser e de agir e a novas percepções da realidade.

A criatividade possibilita viver melhor, entender os acontecimentos de modo diferente, procurar soluções práticas e positivas para os problemas, tanto a nível pessoal como social. Uma pessoa criativa é aquela que tem a previsão, a determinação e, por vezes, a sorte necessária para desenvolver com consistência ideias que, muito embora não sejam conformes com a moda do momento, podem, com o tempo, atingir uma grande aceitação social (Sternberg, 1997).

A educação criativa pretende criar personalidades dotadas de iniciativa, cheias de recursos e de confiança, tolerantes e prontas para afrontar problemas pessoais, interpessoais ou de qualquer outra natureza (Guilford, 1991). Este autor propõe a criatividade como a chave da educação no seu sentido mais amplo, bem como a solução dos problemas mais sérios da humanidade. Por essa razão, Rogers e 
Freiberg (1986) são contra as correntes pedagógicas que propugnam que a criança deve ir à escola para ser ensinada e não para debater problemas nem para escolher opções. Isto é, são contra o sistema tradicional, rígido e burocrático, que não satisfaz as necessidades reais da nossa sociedade.

O que dissemos sobre a conexão existente entre a aprendizagem num contexto que tenha em consideração o factor estético e o interesse que parece existir em formar cidadãos criativos, leva-nos a considerar que os aspectos estéticos ligados à educação são algo mais do que uma componente curricular aditiva. A consideração da variável estética é uma peça fundamental no processo de ensino -aprendizagem, não é apenas por ser considerada um conteúdo em si própria, nem porque optimiza os resultados da aprendizagem, mas porque os processos necessários para nos adaptarmos às mudanças do ambiente -social, físico e cultural- estão ligados às capacidades criativas do homem.

Fomentar experiências estéticas na escola favorece a mudança de atitudes tornando-as mais positivas, mais activas, mais imaginativas e criadoras (Wong, 2007).

Daí a importância de possibilitar e fomentar nos alunos a possibilidade de desenvolverem laços afectivos com o que observam, promover a expressão de ideias, bem como o descobrimento das componentes estéticas por meio da reflexão e do diálogo (Juanola e Balada, 1987).

Assim, Bronstein e Vargas (2001) defendem que é necessário criar um ambiente favorável para que o desenvolvimento se torne num processo saudável, seguro e estimulante. Baseando-nos no facto de que nos relacionamos com o ambiente externo desde o primeiro dia de vida, torna-se necessário motivar desde tenra idade as crianças para explorar e experimentar o mundo, desenvolvendo, deste modo, as competências necessárias para encarar desafios e responsabilidades no futuro.

Outro aspecto importante é favorecer a multiplicidade e diversidade de experiências e imagens dada sua importância para a vida das pessoas (Socher, 2007). Existem várias e interessantes experiências pedagógicas que têm por estimular o desenvolvimento da criatividade.

A título de exemplo, referimos os trabalhos de Edwar de Bono (1986), que refere como imprescindível para o desenvolvimento do pensamento os seguintes elementos: A liberdade de expressão; a ausência de inibições; o evitar juízos críticos de avaliação; e a estimulação de ideias durante o processo criativo.

Carl Rogers (1991) acrescenta a de Bono as seguintes ideias sobre as condições que propiciam o desenvolvimento da criatividade: $O$ trabalho em grupo; o clima de confiança, de aceitação e de respeito à pessoa; a independência e a liberdade de projectar e seleccionar opções diversas.

Como muito bem diz Vecina Jiménez (2006) a alegria e a criatividade permitem o desenvolvimento e o treino de habilidades físicas (força, resistência, precisão), de habilidades psicológicas e intelectuais (compreensão de normas, memória, autocontrolo) e de habilidades sociais necessárias para o estabelecimento de relações de amizade e de apoio. 
O desenvolvimento da criatividade deve, em nossa opinião, iniciar-se desde cedo e estender-se a todas os grupos etários. O desenvolvimento criativo revelase de estrema importância em momentos de escassez e de conflito, nos quais ter estratégias de velocidade, de resistência, de amigos, de capacidade de inovação, podem constituir a diferença entre viver e morrer.

\section{ESTÉTICA E SENSIBILIDADE}

A educação para a sensibilidade através do estabelecimento de conexões com os outros, sejam eles sujeitos ou objectos, favorece determinados valores que se repercutem positivamente no processo de desenvolvimento pessoal.

Para entender melhor a contribuição da educação da sensibilidade estética para o desenvolvimento crianças, jovens e adultos vejamos as propostas de Hernán Errázuriz (2006). Segundo este autor, a presença na escola desta dimensão consegue que os alunos se realizem como pessoas, sendo capazes de ter uma avaliação estética própria, de distinguir a beleza na natureza, na cultura e nas artes, de apreciar a diferença e de gerir melhor as suas próprias emoções e sentimentos. A sensibilidade estética faz parte de uma visão humanista e não instrumental da educação, atende a âmbitos profundos da vida humana que tiverem um espaço destacado na formação das novas gerações, dos gregos à actualidade, e que hoje ficaram postergados pela prevalência sem contrapeso de uma lógica restritiva da produtividade económica.

O processo da formação de indivíduos e grupos sociais deve ter como alvo a educação da sensibilidade, dado que esta possibilita a capacidade de assombro perante mundo, a possibilidade de sentir a beleza e de dar forma à expressão criativa (Bravo de Hermelin, 2007).

A contemplação estética é um processo complexo mas de extrema importância para a educação. Este conceito implica o desenvolvimento dos sentidos, a capacidade de atenção, agudeza de espírito, suspeita e aceitação, permitindo a "determinação última de toda a criatura racional é a unidade absoluta, a constante identidade e harmonia" (Fichte, 1913, 236) é um momento de ataraxia, de suspensão da razão. O homem é o único ser com capacidade de se deslumbrar, e não podemos esquecer que foi através desta capacidade que surgiu toda a cultura. É a partir desta experiência contemplativa, essencialmente estética, que podemos ter uma percepção mais intensa dos contextos objectivos e subjectivos.

Abrem-se assim possibilidades de, nesse espanto e nesse sentimento, poder criar partilhar e dialogar com o outro, seja ele o criador ou o que contempla, o que sente ou o que se comove. Assim a "experiência estética também mobiliza a razão, a emoção, a paixão, o sentimento, o desejo e a imaginação, propiciando uma rica mobilização no sujeito entre o sentido e o pensado, o que percebido e o imaginado, consciente e inconsciente, o desejo e a sua simbolização" [...] "O sentimento não só revela a profundidade do objecto estético mas, correlativamente, produz a nossa própria profundidade vital”(Gil Marin, 2007, 4). 
Descobrimos por meio da sensibilidade estética novas propriedades e qualidades, novas relações entre sujeitos e objectos que, pela riqueza e variedade humana, adquirem novas significações.

De facto, Vásquez (2008) contempla a estética como o estudo de um modo específico de apropriação da realidade, em que se salientam as questões ligadas à sensibilidade, inclusivamente vinculadas a outras formas de apropriação e às condições históricas, sociais e culturais.

Por essa razão, a educação da sensibilidade permite-nos desenvolver a acção de reflectir, julgar e criticar, a partir do estabelecimento de novos modos de olhar, normalmente mais solidários e tolerantes, a propósito das vivências individuais e sociais,

em determinados momentos das nossas vidas todos nós vivemos numa situação estética, por mais ingénua, simples ou espontânea que seja a nossa atitude como sujeitos nela. Perante a flor que se dá de prenda, o vestido que se escolhe, o rosto que enleia, ou a canção de que gostamos, vivemos essa relação peculiar com o objecto, à qual chamo "situação estética", e vivemo-la guiados por certa consciência ou ideologia estéticas (Vásquez, 2008, 17).

Já Schiller afirmava: "A formação da sensibilidade supõe, por tanto, a necessidade mais permanente da época, não apenas por ser um meio para melhorar o conhecimento, eficaz para a vida, mas também porque desperta a própria melhoria do conhecimento" (Schiller, 1920, 50).

Por isso podemos afirmar que a experiência estética não se liga só à sensibilidade mas também ao conhecimento e à razão. Este é um desafio fundamental, enquanto a razão e a sensibilidade forem rivais, ou enquanto prevaleça uma em detrimento da outra, o ser humano pode considerar-se debilitado e desequilibrado, consegue ser livre nem autónomo (Jiménez, 1986). Um homem excessivamente racional, que só obedece às imposições do intelecto, precisa de uma moral, de uma religião, de uma ordem transcendental. Em compensação, um indivíduo sensível de mais, vítima de um excesso de sentimentalismo, precisa da ciência e de regras bem arrumadas capazes de lhe inculcar alguma razão.

Todos estamos inevitavelmente atados às condições e às características do contexto social, que nos constitui como sujeitos de um determinado tempo e lugar e, simultaneamente, como parte de uma história particular (Zanella, 2007). Mas, embora estejamos sujeitos à realidade, a realidade não nos determina, já que o controlo e a dependência não som absolutos; existe sempre a possibilidade de fuga, actos de resistência que provocam rupturas com o instituído e que se apresentam como fundamentos para a reinvenção de nós próprios e da própria realidade. Finalmente, modos de existência aprendidos nas dinâmicas do poder e do saber, jamais são completamente compactos e definitivos, pelo contrário, sempre existem neles espaços, fendas, possibilidades éticas e estéticas não pensadas pelos saberes e poderes em jogo (Fischer, 2002, 154). 
Consideramos que a dimensão estética, enquanto formação da sensibilidade, é fundamental, necessária ao compromisso com a própria vida, com a riqueza e multiplicidade da existência e da realidade humana, que se constrói por meio da actividade singular e colectiva, em contínua transformação. A sensibilidade mobiliza o sujeito para a luta contra qualquer forma de sujeição, promove a resistência contra a humilhação e, ao mesmo tempo, possibilita novas formas de vida.

\section{ESTÉTICA E IMAGINAÇÃO}

A educação estética fundamentada na imaginação e na criatividade permite, segundo Vygotski (1982), chegar à maturação dos processos primários de tipo mítico-fantástico e facilita nas diferentes fases da vida, a estruturação autónoma e sem estereótipos das linguagens simbólicas. Para o autor, a imaginação como fundamento da actividade criativa manifesta-se em todos os aspectos da vida cultural e facilita a criatividade artística, científica e técnica.

Estas possibilidades são produzidas por pessoas concretas nos actos de resistência, na invenção diária de novos desejos, novas convicções, novos modos de ser e de estar, tanto singulares quanto colectivos, não necessariamente planeados e intencionais que se traduzem em modos diferentes "de adicionar, de trabalhar, de criar sentido, de inventar dispositivos de valorização e de auto-valorização" (Pelbart, 2003, 23).

Para atingir estas metas, são necessários tanto a imaginação como os processos de criação. A imaginação considera-se, conforme as contribuições de Vygotski (1982), como uma actividade psicológica formada por complexos processos de pensamento nas suas relações, igualmente complexas, com a emoção, e por tanto é fundamental para a recreação da realidade. É a actividade através da qual o sujeito se (re)constitui e, deste modo, se objectiva através de processos criativos, é condição para a transformação da realidade social onde participa e actua.

A relação entre imaginação e aprendizagem é evidente, aprendemos melhor as coisas que formam parte do nosso imaginário (Piaget, 1961). Ela dá vigor às impressões miméticas através da visualização, do ritmo, da dramatização e do estabelecimento de outras ligações. A imaginação reforça a memória, dirige a aprendizagem e estabelece relações entre as associações que se realizaram anteriormente. Se através da memória estas relações são as mesmas que se associaram quando se produziu a impressão recordada, a imaginação origina uma reprodução vivida (Martín, 1982). Se a reprodução vívida, de passadas impressões, se combina com novos aspectos das associações, teremos uma imaginação criativa. Se das associações experimentadas se derivam aspectos não experimentados, falamos de inovação.

As tecnologias permitem um novo poder à imaginação uma vez que possibilita a produção colectiva e socialmente reconhecível (Harris, 2005). Mas existe uma discordância entre o mundo imaginado, que ajudam construir, e a situação 
real na qual os objectos são construídos e expostos. Podemos vê-lo claramente se analisarmos os vídeo jogos.

A capacidade de gerar alternativas e solucionar consequências, aparece durante os primeiros períodos de desenvolvimento infantil e estende-se ao longo da vida.

A intenção de Harris, afastando-se das contribuições de Piaget, é demonstrar que a análise contemporânea do desenvolvimento cognitivo é muito estreita, os mitos sobre a suspensão da realidade objectiva e da suposta confusão com os mundos imaginários que as crianças geram, bem como os adultos, são trabalhados a fundo pelo autor.

Imaginar é atrever-se a pensar que as coisas podem ser de outro modo (Greene, 2005) e aí começa não só o complicado mundo da liberdade mas também o do conhecimento e o do compromisso.

Os educadores não podem conformar-se e viver como simples empregados administrativos ou funcionários. Na formação destes profissionais, bem como em todas as profissões, é necessário ter em consideração a procura incessante, o desejo de melhorar as situações, desses e dessas que tentamos formar e do mundo que todos nós partilhamos. Não podemos conformar-nos com reproduzir o estado actual de coisas.

Outros autores como Egan (1999) ou Beetlestone (2000) investigam a importância da criatividade e da imaginação na escola e apontam que é preciso ter-se em conta as características da vida imaginativa de todas as pessoas. Egan (1999) estuda a nossa capacidade de conceber o possível para especificar o real e, deste modo, elaborar novas práticas e novas visões do mundo a partir de uma liberdade assim conseguida. Noutro texto (Egan, 1994) afirma que à escola se pedem objectivos contraditórios: socialização, transmissão de conhecimentos e desenvolvimento das capacidades pessoais de cada aluno. O que implica uma função normativa de socialização e, ao mesmo tempo, que se estimule o desejo de questionar os próprios fundamentos da vida em sociedade.

\section{LINHAS DE TRABALHO}

De tudo o que foi exposto deduz-se que, para obter um desenvolvimento harmónico e integral dos indivíduos, devem incorporar-se no sistema de educativo, em todos os níveis e modalidades, meios expressivos como a música, a pintura, a escultura, a dança e a dramatização, ou seja, é necessário integrar a educação estética ao longo de todo o processo educativo. Para além disso pensamos que os próprios locais onde vivemos ou trabalhamos, devem converter-se em factores estéticos de motivação, tornando-se agradáveis e acolhedores de forma a educar o gosto e a fomentar elementos de pertença, para que os indivíduos se sintam integrados de forma harmónica no todo. 
A arte na educação é um factor determinante do processo de desenvolvimento sensitivo e intelectual, e constitui um meio fundamental para desenvolver capacidades de expressão e comunicação, de pensamentos e sentimentos (Vera Verján, 2008). Quando se educa, deve começar-se a trabalhar a criatividade, a expressão e o desenvolvimento da apreciação estética, elementos que conseguem integrar a personalidade dos educandos e que, por si mesmos, podem chegar a ter uma função terapêutica, ajudando a libertar tensões e a propor soluções criativas na vida diária.

A supremacia do conhecimento fragmentado impede, com frequência, operar o vínculo entre as partes e a totalidade, impedindo a criação de conhecimentos capazes de captar os objectos nos seus contextos, nas suas complexidades e nos seus conjuntos.

O ser humano é, simultaneamente, físico, biológico, psíquico, cultural e social, esta unidade complexa da natureza humana, encontra-se totalmente desintegrada na educação por disciplinas e não permite entender o que significa ser "humano", objectivo essencial de toda a educação.

Pensamos também que a educação deve conduzir a uma antropo-ética, que partindo da consciência do que é ser humano e da compreensão da sua condição inter-solidária, se torne uma base segura da educação para a paz, na consciência de que o nosso destino é comum por essência e por vocação.

Para conseguir o que propomos, consideramos necessário uma série de mudanças no sistema educativo:

- Partir das necessidades individuais e concretas do aluno, das suas vivências e características do seu contexto ambiental, que devem ser ponto de partida para a construção de um novo estilo de conhecimento, mais harmonioso e, nesse sentido, mais estético.

- Promover mecanismos e projectos que possibilitem a análise da realidade de perspectivas e ângulos diferentes, observando pormenores que podem passar desapercebidos e que, no entanto, podem favorecer a criatividade e a inovação pessoal e do grupo.

- Ler a realidade a partir das emoções e dos sentimentos e não só através dos conceitos abstractos do conhecimento e da razão.

- Avaliar diferentes perspectivas de análise da realidade o que supõe destruir certezas e convicções, e procurar pontos de encontro na diversidade.

- Experimentar novas formas de olhar, escutar, sentir e objectivar-se criativamente.

- Perder o medo ao desconhecido, abrir-se a novas possibilidades, ao risco e ao fracasso, superando medos e limitações, bem como, a ansiedade e as tensões que isto pode causar.

- Desenvolver actividades transversais que favoreçam e promovam a manifestação de diferentes modos de analisar e ver a realidade a partir dos sentidos, bem como, a reflexão sobre os caminhos éticos que as atravessam. 
Para conseguir estas metas, é preciso o reconhecimento da importância da educação estética e da actividade criativa como essenciais ao desenvolvimento humano, ou seja, "a organização das nossas aptidões intelectuais, o requinte da nossa habilidade perceptiva e a íntima relação com a nossa capacidade emocional podem considerar-se como desenvolvimento estético" (Lowenfeld, 1972, 366).

Propomos uma educação que parta dos sentidos, sobre os quais se baseia a consciência e, a final de contas, a inteligência e o juízo humano. A estética e a arte surgem como alternativas válidas para a devolução da confiança, da auto-estima e da possibilidade de encarar o futuro com mais optimismo, ou seja, para a promoção de um projecto educativo que se pretende crítico e emancipatório.

\section{REFERÊNCIAS BIBLIOGRÁFICAS}

AGUiRRE, L. (2000) Estereotipo, integración cultural y creatividad, en HERNÁNDEZ BELVER, M. e SÁNCHEZ MÉNDEZ, M. Educación artística y arte infantil. Madrid, Fundamentos.

ARNHEIM, R. (1993) Consideraciones sobre la Educación Artística. Barcelona, Ediciones Paidós Ibérica S. A.

AZNAR, V. e PINO-Juste, M. R. (2009) Estética y educación para la salud. Estrategias y actividades para el aula. Alambique, 15 (62), 109-117.

Balada Monclús, M. e JuANOla TerRadielles, R. (1987) La educación visual en la escuela. Barcelona, Paidós/ «Rosa Sensat”.

BAlADA, M. y JUANOla, R. (1987) La educación visual en la escuela. Barcelona, Paidós.

BARba TÉllez, M. N. e García BARgado, M. (2006) Creatividad y apreciación estética en la edad preescolar. Revista Recre@rte, 6 diciembre. Consultado el 3 de marzo de 2011. http://www.iacat.com/Revista/recrearte06.htm.

BeEtlestone, F. (2000) Niños creativos, enseñanza imaginativa. Madrid, La Muralla, 2000.

Betancourt, J. e VAladez, M. D. (2000) Atmósferas creativas: juega, piensa y crea. México, Editorial Manual Moderno.

Bezerra Barbosa, F. M. (2008) Aesthetics and Critical Theory: Suggestions for an Adult Education Pedagogy, en Teaching and Learning, International Association for the Scientific Knowledge. Consultado el 3 de junio de 2011. http://www.iask-web.org/tl08/programme.html.

- (2011) Da Educação da decepção à educação do optimismo. Recuperar o verdadeiro sentido da educação. Revista de Investigación en Educación, 9, (1), 48-55.

Birkhoff, G. D. (1933) Aesthetic Measure. Harvard, University Press.

BRAVO DE HERmelin, M. E. (2007) El patrimonio cultural, reto para la educación estética. I Foro Departamental de Patrimonio, realizado por la Secretaría de Educación para la Cultura de Antioquia -Dirección de Fomento a la Cultura- Universidad Nacional, Facultad de Ciencias Humanas y Económicas. Medellín, septiembre 2007. Consultado el 3 de marzo de 2011 http://www.revistaaleph.com.co/article.php3?id_article=186.

BRONSTEIN, V. e VARGAS, R. (2001) Niños creativos. Barcelona, Editorial RBA Libros.

CARANFA, A. (2007) Lessons of Solitude: The Awakenning of Aesthetic Sensibility. Journal of Philosophy of education, 41 (1), 113-127. 
Collelldemont i Pujadas, E. (2002) Educació i experiència estética. Barcelona, Eumo Editorial.

Crespo Comesaña, J. e Pino-Juste, M. R. (2003) El diseño y estructuración del espacio como factor de las problemáticas de salud en el ámbito comunitario y escolar. Revista GalegoPortuguesa de Psicología e Educación, 8 (10), 126-141.

- (2009) La estética de las edificaciones escolares en la educación infantil en la Comunidad Autónoma de Galicia. Revista de Educación, 349, 485-511.

Danner, D. D.; SNOwdon, D. A. e Friesen, W. V. (2001) Positive emotions in early life and longevity: Findings from the nun study. Journal of Personality and Social Psychology, 80, 804-813.

DE BOno, E. (1986) El pensamiento lateral. Manual de Creatividad. Barcelona, Paidós.

EGAN, K. (1994) Fantasia e imaginación: su poder en la enseñanza. Madrid, Morata-MEC.

- (1999) La Imaginación en la Enseñanza y el Aprendizaje para los Niños Intermedios en la Escuela. Amorrortu Editores.

FichTe, J. G. (1913) El destino del sabio. Madrid, Librería Victoriano Suárez.

FISCHER, R. M. B. (2002) O dispositivo pedagógico da mídia: modos de educar na (e pela) TV. Educação e Pesquisa, 28 (1), 151-162.

FLORES, L. (1996) Experiencia estética y expresión creadora en el dialéctico espacio de la educación. Paideia: Revista de filosofía y didáctica filosófica, 17 (34), 9-20.

Florida, R. (2002) The Rise of the Creative Class. New York, Editorial Basic Books.

GENNARI, M. (1997) La Educación estética. Barcelona, Paidós.

GIL MARÍn, F. J. (2007) Pensamiento artístico y estética de la experiencia... repercusiones en la formación artística y cultural. Conferencia magistral número 7. Página web Congreso de formación artística y cultural. Facultad de Artes de la Universidad de Antioquia y la Secretaria de Educación para la Cultura-Dirección de Fomento a la Cultura, UNESCO.

GIROD, M. (2007) Connecting art and science: Teaching with sublime. Science and Children, 44 (5), 26-29.

GREENE, M. (2005) Liberar la Imaginación. Ensayos sobre Educación. Barcelona, Graó.

GUILFORD, J. P. (1991) Creatividad y educación. Barcelona, Paidós.

GUTIÉRREZ PÉREZ, R. (1998) La estética del espacio escolar. Barcelona, Oikos-Tau S. A.

Hargraeves, D. J. (1991) Infancia y Educación Artística. Madrid, Morata.

HARRIS, P. (2005) El funcionamiento de la imaginación. México, Fondo de Cultura Económica.

Haug, W. F. (1989) Publicidad y consumo. Crítica de la estética de mercancías. México, Fondo de Cultura Económica.

HERAS, L. (1997) Comprender el espacio educativo. Investigación etnográfica sobre un centro escolar. Málaga, Aljibe.

HERNÁN ERRÁZURIZ, L. (2006) Sensibilidad estética: un desafío pendiente en la educación chilena. Chile, Instituto de Estética UC.

Herrán Gascón, A. de la (2000) Hacia una Creatividad Total. Arte, Individuo y Sociedad, $12,71-89$.

JimÉNEZ, J. (1986) Imágenes del hombre. Fundamentos de Estética. Madrid, Tecnos.

LIPOVETSKY, G. (2008) La sociedad de la decepción. Barcelona: Anagrama.

Lowenfeld, V. (1972) Desarrollo de la capacidad creadora. Buenos Aires, Kapelusz.

MARÍn, R. e DE LA TORRE, S. (1991) Manual de la Creatividad. Barcelona, Editorial Vicens Vives.

Martín, M. (1982) Semiotica dell'imagine e pedagogía. Press Universitaires de France. 
MASLOW, A. (1983) La personalidad creadora. Barcelona, Editorial Kairós.

Mitjáns MarTínez, A. (1995) Creatividad, Personalidad y Educación. La Habana, Editorial Pueblo y Educación.

Moles, A. (1976) Teoría de la información y percepción estética. Madrid, Editorial Jucas.

MONREAL, C. (2001) Qué es la creatividad. Madrid, Editorial Biblioteca nueva.

MORIN, E. (1999) Los siete saberes necesarios para la educación del futuro. Paris, UNESCO.

ORIOL DE AlARCón, N. M. (2001) Estética y creatividad en la educación ante el nuevo milenio, en AA. VV. La educación artística, clave para el desarrollo de la creatividad. Madrid, Ministerio de Educación, Cultura y Deportes. Subdirección General de Información y Publicaciones, 9-24.

- (2005) Educación estética y artística, en Ruiz BERrio, J. e VÁzQuez Gómez, G. (coords.) Pedagogía y educación ante el siglo XXI. Madrid, Universidad Complutense de Madrid, 521-548.

PAREYSON, L. (1997) Els problemes actuals de l'estètica. Valencia, Universidad de Valencia.

Pelbart, P. P. (2003) Vida Capital: ensaios de biopolítica. São Paulo, Iluminuras.

PERniola, M. (1997) A Estética no Século XX. Lisboa, Editorial Estampa.

PIAGET, J. (1961) Formación del símbolo en el niño: imitación, juego y sueño. Imagen y representación. México, Fondo de Cultura Económica.

Pino Juste, M. e BeZerra BARBosa, F. (2007) Vida con calidad. Estética y salud, en CiD, J. M. e PERES, A. (eds.) Educación social, animación sociocultural y desarrollo comunitario. Vigo, Universidad de Vigo-UTAD-SIPS, 813-824.

PIRINI, P. (2002) Los recorridos de la mirada: del estereotipo a la creatividad. Barcelona, Ediciones Paidós Ibérica S. A.

Platón (361-347 a. C.) Las leyes. Traducido por Fernández Galiano, M. (2002). Madrid, Alianza.

POPPER, F. (1989) Arte, acción y participación. Madrid, Akal.

Quintana Cabanas, J. M. ${ }^{a}$ (1993) Pedagogía Estética. Concepción antinómica de la Belleza $y$ del Arte. Madrid, Dykinson.

RAY, P. H. y ANDERSON, S. R. (2000) The Cultural Creatives. New York, Editorial Harmony Books.

READ, H. (1996) Educación por el arte. Barcelona, Paidós.

- (2007) El significado del arte. Editorial Losada, S. A.

Rogers, C. y FreIBERG, J. H. (1996) Libertad y creatividad en la educación. Barcelona, Paidós.

ROGERS, C. R. (1991) Libertad y creatividad en la educación: en la década de los ochenta. Barcelona, Paidós.

Roura-Parella, J. (2002) El plaer estètic i la creació artística. Barcelona, Universitat Ramon Llull.

Ruiz Ruiz, J. M. (1994) El espacio escolar. Revista Complutense de Educación, 5 (2), 93-104.

SCHILLER, F. (1920) La educación estética del hombre (trad. García Morente). Madrid, Ed. Calpe.

- (1968) La educación estética del hombre. Madrid, Espasa-Calpe.

SOcher, D. (2007) A Picture Is a Patchwork of Color Laid Out in a Private Space in Which Lie Flat Imitations of Life. Journal of Aesthetic Education, 41 (2), 105-112.

STERNBERG, R. (1997) La Creatividad en una cultura conformista. Barcelona, Paidós.

SuÁREZ, M. (1987) Los castigos y otras estrategias disciplinares vistos a través de los recuerdos escolares. Revista de Educación, 282, 301-311. 
TOURIÑÁn, J. M. y LONGUEIRA, S. (2010) La música como ámbito de educación: educación "por" la música y educación "para" la música. Teoría de la Educación, 22 (2), 151-181.

VÁsquez RoccA, A. (2008) La crítica de arte y la estética contemporánea. Consultado el 5 de marzo de 2011. http://revista.escaner.cl/node/792.

Vecina Jiménez, M. L. (2006) Emociones positivas. Papeles del Psicólogo, 27 (1), 9-17.

VERA VERJÁN, B. L. (2008) El arte: factor determinante en el proceso educativo. Consultado el 5 de marzo de 2011. http://educar.jalisco.gob.mx/15/15vera.html.

VYGOTSKI, L. S. (1982) La imaginación y el arte en la infancia. Madrid, Akal.

Wong, E. D. (2007) The Rebirth of Cool: Toward a Science Sublime. The Journal of Aesthetic Education, 41 (2), 67-88.

ZANELlA, A. V. (2007) Educación estética y actividad creativa: herramientas para el desarrollo humano. Univ. Psychol., 6 (3), 483-492. 